soft money spend of over $£ 1 \mathrm{~m}$, attests to the importance which is attached to research by the academic staff, and helps to provide an infra-structure for research activities by the trainees. There is ready access to statistical advice, and regular meetings of the Research Society.

However, none of this would work if it were not for our annual course called "Choosing a Research Project", first described on thse pages ten years ago (Bulletin, 1981, 5, 148). This course continues to provide every trainee who wants one with a research project, and we would advise places which wish to catch up to imitate it.

The basic idea is quite simple. Each week the course is addressed by a different potential supervisor who starts by describing the problems surrounding oneperson projects in the particular field, and lists the projects that still need doing. In the second part of the afternoon a trainee describes how s/he would carry out an actual project that has been assigned by the supervisor at a meeting two or three weeks earlier. At the end of the afternoon the trainee is asked whether they would like the project they have thought about; if not, it is offered to the class.

The success of the course is its symbiotic nature: supervisors need trainees to help them with fieldwork, and trainees need help from a more experienced person in order to think of a worthwhile idea and bring it to a satisfactory conclusion. By the end of the term each trainee has heard from a wide range of supervisors and has listened to a bewildering variety of ideas for one-man projects.

It remains to be seen whether our research record will remain as strong when the only real manpower gateway is between SHO and registrar appointments, since it would be unreasonable to expect an SHO to have made a start on a project. However, we suspect that there will always be competition for more desirable jobs, and that provided the training climate favours research, it will continue to flourish.

School of Psychiatry and Behavioural Science

DAVID GOLDBERG

University of Manchester

Manchester M20 8LR

\section{Audit of research}

DEAR Sirs

Audit is spreading (Junaid \& Daly, Psychiatric Bulletin, June 1991, 15, 353-354). It is right that research activity is audited. This is particularly so when one considers the quantity of research literature that is produced annually. Junaid \& Daly, however, have focused on quantity to the exclusion of quality.

Such an emphasis is surprising since audit has traditionally been concerned more with the maintenance of standards. Should this not also be so of research? It may well be that quality in research is difficult to measure. However, if audit of research is to be repeated in the future then some attempt should be made. I would suggest that useful data is currently in the hands of editors.

While quality levels for research have never been formally agreed upon, in practice they have been set by editors of journals. Quality is reflected to a large degree by 'publishability'. All this is to point to the obvious - that editors have been expert auditors for years. The difference is that, unlike auditors, their glory has gone unnoticed. Perhaps their time has come?

While Junaid \& Daly perform a quantitative audit on those articles accepted for publication they omit an analysis of the more important data: the amount of research that is refused. Such data is the domain of the editor-cum-auditor. Surely such an analysis is of greater evaluative importance. An audit of the number of successful operations in NHS hospitals would surely say little if it excluded the number that had failed.

I hope Drs Junaid and Daly will forgive me for auditing their audit.

\section{North Wales Hospital}

BRIAN WILLIAMS

Denbigh, Clwyd

\section{Dear Sirs}

Dr Williams is correct to address the issue of failed research. Currently trainees spend countless hours on projects that have no hope of succeeding. In a climate where research has to be done to improve CVsit is perhaps understandable that research undertaken for the wrong reason often fails. Professor Goldberg's Manchester Scheme, where research is given high priority, money is available and a structured approach to supervision is welcome news. While it may be impossible to accurately quantify the time, effort, energy and number of failed projects it is possible to determine factors which positively contribute to productive research.

Perhaps it is time that trainees look more carefully at the research activity of potential training rotations. In order to attract the right sort of candidate, and indeed provide all round training, all rotations need to look more closely, and more carefully at the degree of research supervision available and provided.

We arrived at only one conclusion in our paper, that is, there is a wide variation of productive research by trainees in psychiatry in the United Kingdom. We suggested that further work needs to be carried out to identify those factors which encourage trainees to successfully complete research. Professor Goldberg has listed four factors that he considers contribute to a high level of productivity for trainees in his region. It would appear a fairly 
simple matter to introduce some or all of these factors into other schemes around the country. Increasing research productivity might lead to the conclusion that these are important contributory factors.

Queen's Medical Centre

Ola Junaid RACHEL DALY

Nottingham NG7 $2 \mathrm{UH}$

\section{Trainees' research}

\section{DEAR SIRS}

I read with a growing sense of disquiet Shôn Lewis' paper 'A Prospective Controlled Trial of Trainees' Research' (Psychiatric Bulletin, August 1991, 15, 478-480). What are the ethical implications of using trainces in research without obtaining their prior consent? This is particularly relevant as the consequences of this intervention may have significant positive outcome on their careers. Although there was capacity for ten trainees on the course, eight were selected. In effect two trainees were excluded from a course which improved performance on objective indicators of research activity. Excluding intervention universally accepted as 'of benefit' would not be permitted by an ethical committee looking after the interests of patients; trainees deserve at least the same protection.

Dr Lewis raises the very important question, should a publication be so important in determining career progression? Can psychiatry afford to lose those clinicians who combine empathy, diligence and efficiency but have no desire to play the research game? For make no mistake, it has become a game. Authorship may mean nothing more than performing a handful of mini-mental states or a dozen physical examinations. An uncited publication in an obscure journal may be good for the ego and get you shortlisted, but is there a positive correlation with becoming a successful consultant?

Mapperley Hospital

O. JUNAID

Nottingham NG3 6AA

\section{DeAr SiRs}

While acknowledging Dr Junaid's concern about ethical issues, I may say I did not worry unduly about this. Perhaps I was wrong, but it could be argued that it would be more unethical not to offer trainees a research course at all, or to engage trainees in a research course which was unevaluated.

Dr Junaid also asks whether publications should be so crucial in deciding a trainee's future career. In my experience, clinicians fall into one of two groups on this issue. Some clinicians think that researchers are better clinicians while others think that researchers are worse clinicians. Although not published in the earlier report, I actually undertook a small subsequent study to try and look at the validity of these assumptions. In opting for candidates with publications on their $\mathrm{CV}$, were appointment committees shortlisting the right people? Following the senior registrar appointment committee referred to in the article, which shortlisted 11 candidates out of 32 and was more likely to shortlist those with a publication, I sent questionnaires to each of the 32 applicants. These were sent one month after the interviews and consisted of eight statements which the trainee was asked to rate his or her agreement, from "strongly disagree" to "strongly agree". The statements were constructed with the aim of reflecting the ability and commitment of the trainee as a future clinician and included items such as "I sometimes find it difficult to get on with other staff members", "I am well organised at work", "I am sure that psychiatry was the right career choice", and so on. Trainees were asked to answer anonymously, although whether or not a questionnaire had been completed by a shortlisted or non-shortlisted trainee was known. After two mailings, 24 of the trainees replied $(75 \%)$. The two groups of those who had been shortlisted $(n=8)$ and those who had not $(n=16)$ were compared on their responses with the hypothesis that the shortlisted group would show evidence of more committed attitude to their chosen clinical career. A distinct difference between groups was shown in the response to one item only: "I enjoy every aspect of clinical work". However, this difference was in the opposite direction to that predicted: 14 of the 16 non-shortlisted trainees agreed mildly or strongly with the statement, compared to just 3 of the 8 shortlisted trainees (Fisher's Exact $P=0.004$ ). Thus, such an item reflects clinical commitment, it seems that the committee might not be succeeding in shortlisting the most worthy candidates; although the proper interpretation of this finding is probably not straightforward.

SHôN LEWIS

Charing Cross and Westminster Medical School

St Dunstan's Road

London W6 8RP

\section{"Cannabis psychosis"}

\section{DeAR SIRS}

I was intrigued by Dr Thomas' correspondence (Psychiatric Bulletin, August 1991, 15, 504) on "cannabis psychosis". I could not help speculating on the impetus behind his letter. Is there a major drug problem out there on the mean streets of downtown Pontyclun? And if so, how does this impinge on Dr Thomas whose business address is given enigmatically as, merely, Near Pontyclun. While the nosological status of "cannabis psychosis" is unclear 